\title{
Post-operative use of HME filter-protected open tracheostomy circuit during the COVID-19 pandemic
}

Follow this and additional works at: https://www.journal.acorn.org.au/jpn

Part of the Anesthesiology Commons, and the Surgery Commons (c) (i)

This work is licensed under a Creative Commons Attribution 4.0 License.

\section{Recommended Citation}

Koh, Way Siong; Ng, Irene; and Downing, Megan (2021) "Post-operative use of HME filter-protected open tracheostomy circuit during the COVID-19 pandemic," Journal of Perioperative Nursing: Vol. 34 : Iss. 3 , Article 5.

Available at: https://doi.org/10.26550/2209-1092.1138

https://www.journal.acorn.org.au/jpn/vol34/iss3/5

This Project report is brought to you for free and open access by Journal of Perioperative Nursing. It has been accepted for inclusion in Journal of Perioperative Nursing by an authorized editor of Journal of Perioperative Nursing. 
Post-operative use of HME filter-protected open tracheostomy circuit during the COVID-19 pandemic

\section{Cover Page Footnote}

Conflicts of interest: The authors have no conflicts of interest to declare. 


\section{Authors}

Dr Way Siong Koh

MBBS, FANZCA

The Royal Melbourne Hospital

\section{Dr Megan Downing}

MBBS, GCertClinTeach, BPhysio, FANZCA

The Royal Melbourne Hospital

Dr Irene Ng

MBBS, FANZCA, MClinResearch,

GCertCritCareEcho

The Royal Melbourne Hospital, University of Melbourne

\section{Corresponding author}

Dr Way Siong Koh

MBBS, FANZCA

The Royal Melbourne Hospital waysiong@gmail.com

\section{Post-operative use of HME filter-protected open tracheostomy circuit during the COVID-19 pandemic}

\section{Abstract \\ Introduction}

In the era of the COVID-19 pandemic, the avoidance of aerosol generating procedures (AGPs) is paramount to reduce the risk of viral transmission to staff and other patients. Perioperative management of a new tracheostomy is challenging as routine care, such as suctioning, frequently involves AGPS.

\section{Method}

We developed and implemented an apparatus called the heat and moisture exchanger (HME) filter-protected open circuit. This enabled closed suctioning to be performed and allowed spontaneously breathing patients to be managed with an open circuit in a shared environment while reducing the risk of viral aerosolisation. We performed a prospective observational study of 20 cases, recording the incidence of desaturation ( $<90 \%$ ), apparatus disconnection, apparatus dislodgement and apparatus replacement. The ease of use of the apparatus for recovery nursing staff and patient comfort were measured on a Likert scale.

\section{Results}

There were no incidents of desaturation. There were two circuit disconnections. Apparatus replacement with an alternate circuit was not required for any patient. Most recovery nursing staff agreed or strongly agreed that the apparatus was easy to use and that the apparatus bulk or weight did not interfere with patient care activities. Ninety-five per cent of patients reported that their breathing was comfortable prior to discharge from the Post Anaesthesia Care Unit.

\section{Conclusion}

In conclusion, the HME filter-protected open circuit is a relatively safe, acceptable and practical device to use for spontaneously breathing patients with newly created tracheostomies in the perioperative environment.

Keywords: tracheostomy, post-operative, recovery, theatre, COVID-19, aerosolisation, HME filter

\section{Identified problem}

In periods of high community transmission during the COVID-19 pandemic, changes to nursing practices in the Post Anaesthesia
Care Unit (PACU) have been required to reduce the risks of viral infection for both staff and other patients in the immediate environment? Tracheostomy formations are required for various indications, 
including neck dissection surgery for cancers of the upper airway. The routine management of newly created tracheostomies in an awake, spontaneously breathing patient in the PACU involves oxygenation via a tracheostomy aerosol therapy mask or a high flow humidification device. Their post-operative care is challenging as most interventions required to manage them, such as suctioning, are aerosol generating procedures (AGPS) 2,3. These patients are also more likely to cough postoperatively, leading to droplet and aerosol spread. During the period of increased community transmission of the coronavirus, it was necessary to reduce the performance of AGPs for all patients, including patients who were tested negative for COVID-19, to reduce the risk of viral transmission to staff and other patients. As a result, it was necessary to recover these patients in a negative pressure and isolated environment with airborne precautions ${ }^{4,5}$. This necessitated recovery in the operating theatre, increasing demand on staff and resources and delaying theatre turnover.

\section{Proposed solution}

There was limited literature on the ideal system to manage spontaneously breathing patients with a newly formed tracheostomy in the immediate post-operative period ${ }^{2,3,6-8}$. Based on guidance from available literature, we assembled an apparatus to enable the care of these patients in the PACU environment without the risks associated with AGPS.

The components of our apparatus included an in-line suction device connected to a heat and moisture exchanger (HME) filter followed by a 'T-Bag' oxygen enhancement device (T-bag) before connecting to an oxygen source at $6 \mathrm{~L} / \mathrm{min}$ (Figure 1). This circuit design

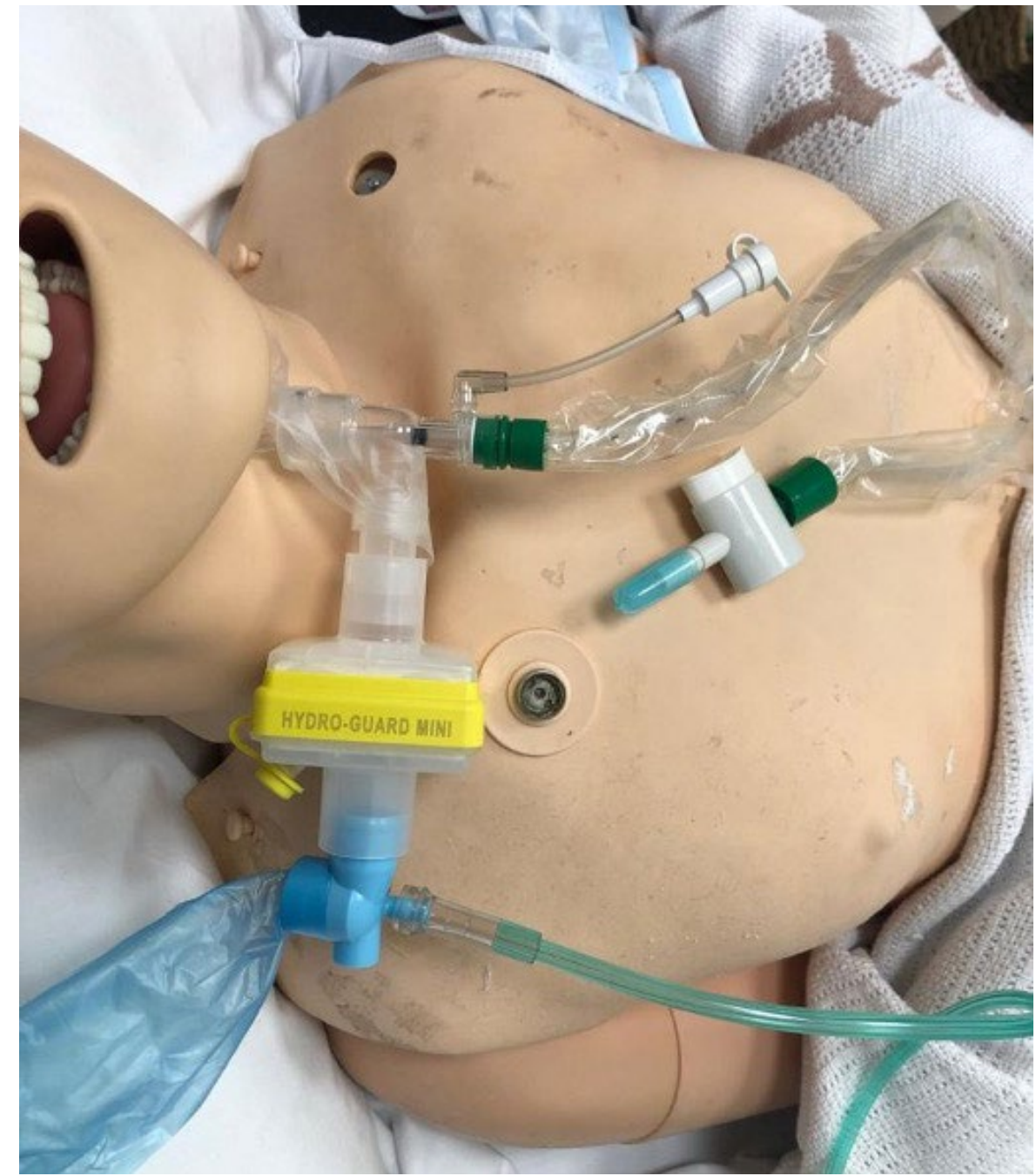

Figure 1: HME filter-protected open circuit

enabled the provision of warm, humidified supplemental oxygen and performance of suctioning without droplet and aerosol generation $n^{3,9-11}$. The T-bag was a lightweight, injection-moulded, polyethylene T-piece and shaped reservoir bag of $300 \mathrm{ml}$ volume which allowed the provision of oxygen supplementation with a fraction of inspired oxygen $\left(\mathrm{FiO}_{2}\right)$ up to 60 per cent, increasing the margin of safety if ventilation is compromised and to compensate for decreased respiratory drive in the immediate post-operative period.

\section{Project plan}

We performed a prospective observational study examining the safety, practicality and patient comfort of using this apparatus. After receiving approval from Melbourne Health Human Research Ethics Committee (QA2020071), we recruited the first 20 consecutive spontaneously breathing adult patients with a newly formed tracheostomy in PACU. We excluded patients who were to be discharged directly from the operating theatre to the intensive care unit with a closed ventilatory system and non-English speaking patients.

The apparatus was attached to the patient immediately after the tracheostomy was formed or at the end of surgery in the negative pressure operating theatre prior to 
transfer to recovery. When the patient was deemed ready for discharge to the ward, the PACU nurse would complete the provided questionnaire (supplemental material), recording adverse events including oxygen desaturation of less than 90 per cent, tracheostomy dislodgement and accidental circuit disconnection. Replacement of airway apparatus for any reason was documented. The practicality and ease of use of the apparatus and whether its bulk or weight interfered with patient care activities were assessed using a Likert scale. Prior to their discharge, patients were asked if their breathing was comfortable. Additionally, freetext comments were also collected from PACU nursing staff.

\section{Project successes}

The study was conducted between 27 May 2020 and 20 October 2020, which coincided with the second wave of the COVID-19 pandemic in Victoria, Australia. Twenty cases were included in the study and survey data was completed for all cases. There were no patients that were tested positive for COVID-19. Reassuringly, there were no instances of oxygen desaturation of less than 90 per cent for any patient and no tracheostomy dislodgements occurred. There were two cases of accidental circuit disconnection from the tracheostomy tube. Apparatus replacement with an alternative circuit was not required for any patient. Most respondents agreed or strongly agreed that the HME filter-protected open tracheostomy circuit was easy to use (Figure 2). More than half of the respondents agreed or strongly agreed that the apparatus bulk or weight did not interfere with patient care activities (Figure 2). Almost all patients found their breathing to be comfortable at the end of their stay in the PACU.

The implementation of the HME filter-protected open circuit was straightforward, requiring only simple education of anaesthesia and recovery staff and placement of a graphic illustration in theatres. As all the required equipment was readily available, the sourcing of apparatus components was easy. The apparatus was also immediately compatible with a manual bag valve respirator or mechanical ventilator circuit, should the need for assisted or mechanical ventilation arise.

The apparatus was well received by staff at our institution during the COVID-19 pandemic and saw continued use beyond the study period. Since the implementation

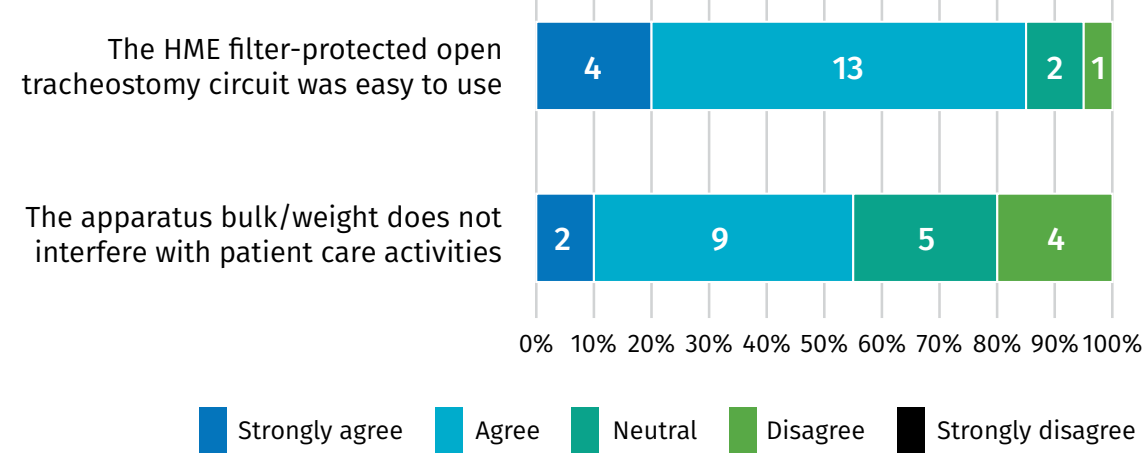

Figure 2: PACU nurse Likert scale responses about ease of use and effect on patient care activities of the apparatus of this apparatus, we were able to nurse unsuspected COVID-19 patients in the shared PACU environment, including performing suction without the consequence of aerosol generation. As a result, we were able to directly improve theatre utilisation and facilitate turnover of cases. Additionally, resources were saved by virtue of reduced need to use personal protective equipment (PPE), as these patients were able to be nursed under droplet rather than aerosol precautions.

\section{Opportunities for improvement}

As the apparatus was a new implementation, graphic illustrations were helpful to have in the operating theatres for reference during tracheostomy insertion. Furthermore, a discussion at the beginning of the case during surgical time-out was important to ensure that necessary equipment was available.

\section{Recommendations}

The HME filter-protected open circuit with closed in-line suctioning was found to be a safe, acceptable and practical device to use for spontaneously breathing patients with newly created tracheostomies in the perioperative environment and could be used during periods of increased risk of viral transmission.

\section{References}

1. Stapleton H. COVID changes to Post Anaesthesia Care Unit nursing practices. JPN 2021;34(2):19-21.

2. McGrath BA, Brenner MJ, Warrillow SJ, Pandian V, Arora A, Cameron TS et al. Tracheostomy in the COVID-19 era: Global and multidisciplinary guidance. Lancet Respir Med 2020;8(7):717-725.

3. Heyd CP, Desiato VM, Nguyen SA, O'Rourke AK, Clemmens CS, Awad MI et al. Tracheostomy protocols during COVID-19 pandemic. Head Neck. 2020;42(6):1297-1302. 
4. Australian and New Zealand College of Anaesthetists (ANZCA). COVID-19 - daily updates [Internet]. Melbourne: ANZCA; 2020 [cited 2020 April 29]. Formerly available from: www.anzca.edu.au/front-page-news/ covid-19-impact-on-anzca.

5. Tran K, Cimon K, Severn M, Pessoa-Silva CL, Conly J. Aerosol generating procedures and risk of transmission of acute respiratory infections to healthcare workers: A systematic review. PloS One 2012;7(4):e35797.

6. ENT UK. NTSP considerations for tracheostomy in the Covid-19 outbreak [Internet]. London: The Royal College of Surgeons; 2020 [cited 2020 December 23]. Available from: www.entuk.org/ntspconsiderations-tracheostomy-covid-19outbreak.

7. David AP, Russell MD, El-Sayed IH, Russell MS. Tracheostomy guidelines developed at a large academic medical center during the COVID-19 pandemic. Head Neck 2020;42(6):1291-1296

8. Mandal A, Nandi S, Chhebbi M, Basu A, Ray M. A systematic review on tracheostomy in COVID-19 patients: Current guidelines and safety measures. Indian J Otolaryngol Head Neck Surg 2020 Sep 28;1-5.

9. Australian and New Zealand Intensive Care Society (ANZICS). ANZICS COVID-19 Guidelines [Internet]. Melbourne: ANZICS; 2020 [cited 2020 Apr 29]. Available from: www.anzics.com.au/coronavirus-guidelines/

10. Brewster DJ, Chrimes NC, Do TB, Fraser K, Groombridge CJ, Higgs A et al. Consensus statement: Safe Airway Society principles of airway management and tracheal intubation specific to the COVID-19 adult patient group. Med J Aust 2020 Mar 16;1.

11. Harrison L, Ramsden J, Winter S, Rocke J, Heward E (for ENT UK). Tracheostomy guidance during the COVID-19 pandemic [Internet]. London: The Royal College of Surgeons; 2020 [cited 2020 April 29]. Available from: www.entuk.org/ tracheostomy-guidance-during-covid-19pandemic. 


\section{Post-operative use of HME filter-protected open tracheostomy circuit during the COVID-19 pandemic}

\section{Supplemental material: Questionnaire}

\section{HME filter-protected open tracheostomy circuit}

Case report form number: Date:

1 Questions for PACU staff regarding safety:

Incidence of desaturation $\mathrm{SpO} 2<90 \%$ :

$\square$ Yes $\square$ No

Incidence of tracheostomy dislodgement:

$\square$ Yes $\square$ No

Incidence of accidental circuit disconnection:

$\square$ Yes $\square$ No

Apparatus replaced with alternative circuit for any reason:

$\square$ Yes $\square$ No

Comments:

\section{Questions for PACU staff regarding satisfaction:}

The HME filter-protected open tracheostomy circuit was easy to use:

$\square$ Strongly Agree $\square$ Agree $\square$ Neutral $\square$ Disagree $\square$ Strongly Disagree

The apparatus bulk/weight does not interfere with patient care activities:

$\square$ Strongly Agree $\square$ Agree $\square$ Neutral $\square$ Disagree $\square$ Strongly Disagree

3 Patient comfort bedside assessment:

When the patient is ready for ward discharge, please ask:

'Is your breathing comfortable?'

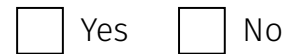

4 General comments from PACU staff or patient: 